\title{
Violência institucional em maternidades públicas sob a ótica das usuárias *
}

Janaína Marques de Aguiar ${ }^{1}$ Ana Flávia Pires Lucas d'Oliveira²

AGUIAR, J. M.; D'OLIVEIRA, A.F.L. Institutional violence in public maternity hospitals: the women's view. Interface - Comunic., Saude, Educ., v.15, n.36, p.79-91, jan./mar. 2011.

This paper presents and discusses data from a survey on institutional violence in public maternity hospitals, conducted in the municipality of São Paulo, Brazil. Twenty-one puerperae were interviewed about their childbirth experiences and the care received, using a semi-structured format. The data showed that the interviewees reported and recognized discriminatory practices and ill-mannered treatment within the attendance at the public maternity hospitals. They reacted through strategies of resistance or accommodation. These experiences are so frequent that these women often come to expect to suffer some type of mistreatment, thus revealing a situation of trivialization of institutional violence.

Keywords: Institutional violence. Maternity. Gender.
Este artigo apresenta e discute os dados de uma pesquisa sobre violência institucional em maternidades públicas, realizada no município de São Paulo.

Foram entrevistadas 21 puérperas, com roteiro semiestruturado contando com questões sobre experiências de parto e assistência recebida. Os dados revelaram que as entrevistadas relatam e reconhecem práticas discriminatórias e tratamento grosseiro no âmbito da assistência em maternidades públicas, reagindo com estratégias de resistência ou de acomodação. Essas experiências ocorrem com tal frequência que muitas parturientes já esperam sofrer algum tipo de maltrato, o que revela uma banalização da violência institucional.

Palavras-chave: Violência institucional. Maternidade. Gênero.

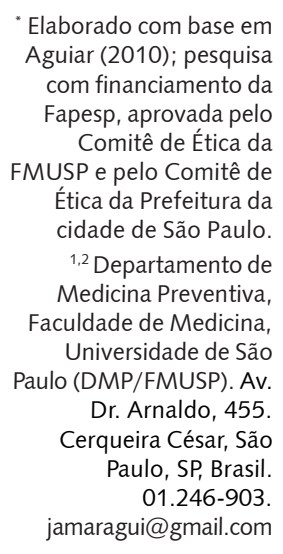


A violência institucional em maternidades públicas tem sido tema recente de estudo em diversos países. Pesquisas demonstram que, além das dificuldades econômicas e estruturais que os serviços públicos de saúde enfrentam, encontram-se, subjacentes aos maus-tratos vividos pelas pacientes, aspectos socioculturais relacionados a uma prática discriminatória quanto a gênero, classe social e raça/etnia (Gomes, Nations, Luz, 2008; Hotimsky, 2007; Diniz, Chacham, 2006; McCallum, Reis, 2006; Teixeira, Pereira, 2006; Domingues, Santos, Leal, 2004; Chiarotti et al., 2003; Tornquist, 2003; D'Oliveira, Diniz, Schraiber, 2002; Diniz, 2001; Comité de América Latina y el Caribe para la Defensa de los Derechos de la Mujer y Centro Legal para Derechos Reproductivos y Políticas Públicas - CLADEM \& CRLP, 1998).

Esta violência, segundo D'Oliveira, Diniz e Schraiber (2002), é expressa desde a negligência na assistência, discriminação social, violência verbal (tratamento grosseiro, ameaças, reprimendas, gritos, humilhação intencional) e violência física (incluindo não-utilização de medicação analgésica quando tecnicamente indicada), até o abuso sexual. Outras pesquisas também apontam, como um tipo de violência, o uso inadequado de tecnologia, com intervenções e procedimentos muitas vezes desnecessários em face das evidências científicas do momento, resultando numa cascata de intervenções com potenciais riscos e sequelas (Diniz, Chacham, 2006; Diniz, 2001).

O parto é um evento social que integra o rol das experiências humanas mais significativas para os envolvidos. Diferente de outros eventos que requerem assistência hospitalar, o parto é um processo fisiológico normal que requer cuidado e acolhimento. Apesar disto, de acordo com a literatura vigente, esse momento é, várias vezes, permeado pela violência institucional, cometida justamente por aqueles que deveriam ser seus principais cuidadores.

A relevância do estudo sobre este tema, portanto, se justifica pela importância de se aprofundar a discussão sobre a violência institucional em maternidades no cenário nacional e seu impacto na história de vida e saúde de mulheres usuárias do Sistema Único de Saúde (SUS). Além disso, esperamos trazer contribuições ao debate sobre a humanização na assistência à saúde, sobretudo no que se refere às políticas de humanização do parto e nascimento.

Neste contexto, o presente artigo apresenta e discute parte dos resultados de uma pesquisa realizada em 2008, para tese de doutorado, na qual foram entrevistadas 21 puérperas assistidas em maternidades públicas da cidade de São Paulo, sobre suas experiências de partos e maus-tratos vividos dentro do serviço de saúde; e 18 profissionais (obstetras, enfermeiras e técnicas de enfermagem) atuantes na rede pública do município, sobre suas experiências profissionais em torno do tema da violência institucional. Trataremos aqui apenas dos dados das entrevistas com usuárias.

Nosso referencial teórico se apoia no conceito de violência definido por Chauí como a:

conversão de uma diferença e de uma assimetria numa relação hierárquica de desigualdade com fins de dominação, de exploração e de opressão. Isto é, a conversão dos diferentes em desiguais e a desigualdade em relação entre superior e inferior. Em segundo lugar, como a ação que trata um ser humano não como sujeito, mas como uma coisa. Esta se caracteriza pela inércia, pela passividade e pelo silêncio, de modo que, quando a atividade e a fala de outrem são impedidas ou anuladas, há violência. (Chauí, 1985, p.35)

Logo, em consonância com este conceito e sob a ótica dos estudos de gênero, estamos considerando que a violência institucional nas maternidades públicas do Brasil é determinada, em parte, por uma violência de gênero, que transforma diferenças - ser mulher, pobre e de baixa escolaridade em desigualdades, uma relação hierárquica na qual a paciente é tratada como um objeto de intervenção profissional, e não um sujeito de seus próprios atos e decisões sobre o que the acontece. Subjaz a este contexto a permanência histórica de uma ideologia de gênero naturalizadora da inferioridade física e moral da mulher e de sua condição de reprodutora como determinante do seu papel social, permitindo que seu corpo e sua sexualidade sejam objetos de controle da medicina (Vieira, 2002; Rohden, 2001; Giffin, 1999). Vale ressaltar que esta dominação do corpo feminino pela medicina, bem como o próprio exercício da violência institucional em maternidades públicas, não se dá sem conflitos e resistências por parte das mulheres/pacientes, como veremos adiante. 
De acordo com Scott (1990), as representações de gênero são elementos constitutivos das relações sociais, como um conjunto de referências que estrutura a percepção e organização de toda vida social concreta e simbólica de cada indivíduo. E, uma vez que estas referências definem diferentes distribuições de poder por meio do controle ou de um acesso diferencial a recursos materiais e simbólicos, este se torna um campo onde a significação do poder por intermédio das relações se articula. Assim, no contexto de nossa pesquisa, vemos o entrelaçamento destas representações de gênero com a violência institucional, como apontado por diversos estudos (Chiarotti et al., 2003; Hotimsky et al., 2002; Wagner, 2001; CLADEM, CRLP, 1998; Jewkes, Abrahams, MVO, 1998; Nogueira, 1994), através, por exemplo, da imagem da mulher que deve aguentar a dor do parto como algo que ela é biologicamente capaz de suportar, e como o preço pelo suposto prazer sentido no ato sexual que deu origem àquela gestação.

Por outro lado, a violência institucional também é determinada pela 'crise da confiança' na área de saúde, entendida como uma crise ética mais global de fragilidade dos vínculos de confiança nas relações entre profissionais de saúde e pacientes, com a despersonalização do cuidado e o predomínio do uso de tecnologia como forma de interação, exacerbando a transformação do paciente em objeto de intervenção (Schraiber, 2008, 1997).

Esta crise, pela qual passa a medicina moderna, caracteriza-se ainda pela dificuldade ou ruptura na interação e na comunicação livre e eficaz (ou efetiva) entre pacientes e profissionais, uma vez que os meios - uso de tecnologia - são transformados em fim.

Neste sentido, outro conceito norteador de nossa análise é o de poder, visto que a violência institucional se dá no seio de relações desiguais de poder: as relações de gênero e a relação profissional de saúde e paciente. Para análise do poder da medicina, enquanto saber legitimado em nossa sociedade, e suas relações com a violência, tomamos, como referência, Arendt (2009), autora também de referência para Chauí (1985). E, para reflexão sobre o exercício do poder médico nas relações interpessoais, nos baseamos em Foucault (1995), que também serve de referência a Scott (1990) em sua discussão sobre gênero e poder.

Para Arendt (2009), o poder surge a partir da ação e da fala em concerto de um grupo e, portanto, é um fim em si mesmo; existe "entre" os homens e não é um bem material ou um atributo, não pode ser acumulado. A autora considera que violência não é uma simples exacerbação do poder. Os dois conceitos se distinguem teoricamente, mas se relacionam na prática. Como instrumento para se alcançar determinado fim, a violência não pode ser a essência nem o fundamento do poder. Segundo Arendt (2009), o poder nunca emerge do cano de uma arma, ou seja, ele nunca emerge de um ato violento, ainda que a violência possa ser usada como recurso para a manutenção do poder. Quando isso acontece, a violência pode manter os postos de poder por algum tempo, mas termina por minar a fonte de geração desse poder - a comunicação entre os sujeitos -, enfraquecendo-o. A relação acaba por ser proporcionalmente inversa: quanto mais violência, menos poder.

O conceito de poder de Arendt, desse modo, ajuda a pensar sobre o poder da medicina e a sustentação de sua autoridade sobre os sujeitos. Já o conceito foucaultiano de poder nos auxilia a compreender "como" este se exerce nas relações cotidianas, ou seja, a microfísica do poder.

Segundo Foucault, o poder é uma forma de ação sobre a ação dos outros e se exerce através das relações. Dessa forma, considera que as relações de poder são da ordem da governabilidade entendendo governar por estruturar a ação dos outros; conduzir a conduta dos indivíduos ou grupos enquanto sujeitos de ação livres (1995). Este é o caso da medicina moderna, como bem demonstra Foucault (2007), na qual o sujeito submete-se de forma voluntária, na maior parte das vezes, às ações e condutas prescritas pelos profissionais médicos sobre seu corpo e seu comportamento.

Foucault (1995) também faz uma distinção entre poder e violência. Para ele, a violência age diretamente sobre um corpo e utiliza a força, a submissão, a coação e até a destruição como formas de ação. Ao contrário do poder, a violência anula as possibilidades de ação e, por esta razão, não pode ser tomada como princípio fundamental ou base para o mesmo. Isto porque, ainda conforme o filósofo, uma condição importante para o exercício do poder é a liberdade do sujeito que sofre sua ação - não há, por exemplo, relação de poder na escravidão porque as possibilidades se saturam, é apenas uma relação de coação física. 
No caso dos profissionais de saúde - e, no topo desta hierarquia, o médico -, o poder exercido se baseia na autoridade cultural e moral que a profissão médica atingiu em nossa sociedade. Essa autoridade está pautada não só em determinados conhecimentos científicos e em tecnologias, como, também, em certos valores e crenças culturais que são compartilhados como verdadeiros socialmente, além de exercerem determinado domínio sobre a conduta moral dos sujeitos. Por essa razão, a autoridade médica tem, como pilares, a legitimidade científica - como dito anteriormente - e a dependência dos sujeitos ao conhecimento que o médico detém, pelo receio de que venham a sofrer consequências desagradáveis caso esta autoridade não seja obedecida (Starr, 1991). A legitimidade e a dependência se dão, sobretudo, porque, em nossa sociedade, a saúde é um valor inequívoco de importância para todos, historicamente monopolizado pela medicina. O poder médico, neste sentido, é produzido pela comunicação entre os sujeitos sociais em condições de desigualdade.

De acordo com Schraiber (2008), esta obediência do paciente à autoridade médica se fundamenta na confiança que se estabelece na relação entre ambos. Desta forma, a medicina, na sua conformação atual (a de uma medicina tecnológica), pode ser entendida como uma "técnica tecnologia dependente", na qual, ao mesmo tempo em que há uma grande valorização da base científica desta tecnologia, há um enfraquecimento do caráter moral dependente da prática. A autora ressalta que esta erosão da qualidade ética das interações entre profissionais e pacientes é responsável pela "crise de confiança" na medicina tecnológica contemporânea, já que técnica e ética são dimensões articuladas da prática médica, fazendo da medicina uma prática social moral-dependente.

Pautados nestes referenciais teóricos, buscamos identificar, nas falas das entrevistadas, a complexa interação entre poder e violência, e como esta interação se molda no cenário da violência institucional cometida em maternidades públicas.

\section{Metodologia}

A abordagem metodológica eleita foi qualitativa. Foram realizadas 21 entrevistas semiestruturadas com mulheres que tiveram seus filhos em maternidades públicas na zona oeste da cidade de São Paulo, em um período de até três meses após o parto. A captação para as entrevistas se deu por indicação de profissionais de três Unidades Básicas de Saúde (UBS), daquela região da cidade, entre as mulheres acompanhadas pelo Programa de Saúde da Família. Todas as entrevistas foram realizadas na residência das informantes, a fim de favorecer os sentimentos de descontração e de segurança dessas mulheres para o relato de suas experiências com o atendimento em maternidades públicas. O critério para o número de entrevistas foi o ponto de saturação do tema, além da quantidade de material obtido e a viabilidade de análise.

O roteiro percorreu, de forma não diretiva, experiências de contato das mulheres com maternidades públicas (acesso, assistência hospitalar, relatos do último parto e partos anteriores) e a ocorrência de maus-tratos, do ponto de vista dessas mulheres. Feito isto, analisamos a intrincada construção de uma postura profissional e institucional violenta contra as pacientes, baseada nas relações destas com os profissionais e nas relações de gênero pelas quais se constroem as representações que fundamentam as práticas sociais, institucionalizadas nos serviços públicos de atenção à maternidade.

Inicialmente, foi realizada uma leitura flutuante de cada entrevista, à medida que eram transcritas. Em momento posterior, realizou-se uma leitura detalhada e uma primeira categorização dos dados de acordo com os eixos temáticos que nortearam o roteiro, pautados no referencial teórico. Essa leitura vertical de cada entrevista em profundidade permitiu o reconhecimento de um perfil particular de cada sujeito entrevistado. Em uma terceira etapa, os dados foram reagrupados conforme o conjunto de respostas, ou seja, uma leitura horizontal das informações possibilitou a comparação de cada grupo de respostas para a mesma questão e a reordenação em categorias de análise mais abrangentes e melhor delimitadas.

O estudo passou pelos Comitês de Ética em Pesquisa da instituição acadêmica à qual está vinculado e da Secretaria de Saúde do Município de São Paulo, respeitando os princípios contidos na Declaração de Helsinki (World Medical Association, 2000). 


\section{Perfil das entrevistadas}

As entrevistadas tinham entre 16 e 42 anos. Mais da metade se declarou afrodescendente, sob as denominações de parda ou morena. No momento da entrevista, a maioria estava em situação conjugal estável e pôde contar com o apoio do parceiro e da família durante a gestação. Cinco entrevistadas contavam com menos de $\mathrm{R} \$ 600,00$ para subsistência familiar. O maior número de depoentes exercia algum tipo de atividade profissional remunerada, o que, em alguns casos, era a única fonte de renda com a qual podiam contar. Todas recebiam alguma contribuição da rede social de apoio para amenizar as dificuldades financeiras e sociais.

No que se refere às experiências de parto, apenas cinco eram primíparas. $\mathrm{Na}$ maioria dos casos, prevaleceu o parto vaginal como via de parto, tanto para as gestações anteriores quanto para a última gestação.

\section{O cuidado: bom $\times$ mau atendimento}

O contato das entrevistadas com o serviço de saúde é pautado por concepções pessoais acerca não só da assistência como do lugar que ocupam na relação hierárquica de poder com os profissionais de saúde, perpassado todo o tempo por questões de gênero. Estas mulheres estão, portanto, em uma dupla relação de poder (como pacientes e como pessoas do sexo feminino), na qual resistem, acomodamse, reproduzem ou contestam ideologias, crenças, valores, e expressam suas próprias representações sobre a vivência do parto.

Na maternidade, estas mulheres experimentam sentimentos distintos e, por vezes, até contraditórios, como: a felicidade pela chegada do bebê e o medo de morrer; o desejo de cuidar do filho, mas também o de ser cuidada pela equipe; a confiança no hospital como o lugar mais seguro para se ter um filho, e a desconfiança de que se é maltratada impunemente nas maternidades públicas.

Assim, a assistência nas maternidades é definida, por nossas entrevistadas, como

${ }^{3}$ Consideraremos aqui ações de suporte como aquelas voltadas para a alimentação, a higiene e outros cuidados pessoais da paciente e do bebê, prestadas, sobretudo, pela equipe de enfermagem. boa ou ruim em relação às ações de suporte ${ }^{3}$, mais frequentemente, à comunicação e à presença ou não de um profissional a maior parte do tempo - o que está de acordo com outros estudos sobre a avaliação das mulheres quanto à assistência em maternidades (Goulart, Somarriba, Xavier, 2005; Domingues, Santos, Leal, 2004; Hoga et al., 2002), que apontam para o relacionamento interpessoal solidário como um dos fatores mais significativos para as pacientes e seus familiares.

O uso de recursos tecnológicos é menos questionado por nossas entrevistadas e, quando o é, na maioria dos casos, elas questionam, mas reconhecem que não possuem o saber necessário para avaliar as intervenções, ainda que, por vezes, desconfiem da sua adequação. O que parece ocorrer é um questionamento da qualidade do uso do conhecimento e dos recursos tecnológicos por um determinado profissional, e não da tecnologia em si (Schraiber, 2008).

"Aí foram fazer o exame do toque, maldito exame do toque. Porque ele foi com toda vontade. Nossa, acho que doeu mais do que na hora do parto. Por isso que eu não gostei dele [médico]. Porque acho que ele não foi com... Se aquilo for delicado, o que não for delicado me matava [...] Aí veio uma médica [...] Tão boazinha, acho que ela tinha uns quarenta anos, mais ou menos, tão boazinha ela era. Ela estourou minha bolsa, fez o exame de toque e eu não senti tanta dor quanto a do homem". (Dina) 
Em suas falas, as entrevistadas ressaltam a importância de uma boa relação com o profissional, fundada: no respeito à sua privacidade, na atenção às suas queixas, em uma comunicação que preze pelo entendimento mútuo, e no uso de tecnologias que elas entendem como necessárias e bem realizadas. Assim, a individualização do atendimento é valorizada por elas como importante para um bom cuidado:

"teve tipo uma estagiária, né, fica com a gente ali, só cuidando de você". (Cida)

“E nas refeições também, elas vinha e colocava uma água pra cada uma [...] Assim, na minha cama, na cama da outra paciente, né". (Olga)

Consideramos que o bom atendimento é identificado a um cuidado que se manifeste a favor de uma integralidade na assistência - o sujeito visto como um todo, e não como um "corpo" em suas partes. Neste sentido, de acordo com Ayres (2004), a dimensão relacional do cuidado é primordial para a eficácia técnica e sucesso prático da assistência. Segundo este autor, há sempre, no encontro entre profissional de saúde e paciente, uma 'objetificação' posta em função da técnica que justifica a ocorrência deste encontro. Ou seja, o paciente vai à procura de um conhecimento técnico científico que o profissional detém. Contudo, o encontro entre esses dois sujeitos não se deve resumir a este processo de objetivação do paciente, visto que isso anularia sua subjetividade, transformando-o em mero objeto de análise diagnóstica e intervenção. Isto é o que ocorre no modelo hegemônico de parto medicalizado, no qual a mulher é vista como uma 'máquina de fazer bebês' e destituída do poder sobre seu corpo ou de qualquer direito à escolha sobre os procedimentos a serem realizados (Wagner, 2001). Logo, a ausência deste cuidado com o paciente enquanto sujeito abre espaço para condutas violentas, de anulação ou impedimento da fala e ação do outro (Chauí, 1985).

Assim, o mau atendimento é definido, pelas entrevistadas, por uma falta de manejo da dor, seja na cesárea ou parto normal (antes, durante e depois do parto); pela ocorrência de complicações, mesmo após a alta médica, que ameacem a integridade física tanto da mulher quanto do bebê, traduzida, pelas entrevistadas, como uma negligência ou o que lhes pareça ser erro médico; pela exposição desnecessária da intimidade da paciente; por dificuldades na comunicação; pela realização de algum procedimento ou exame sem consentimento ou desrespeitosamente; pela discriminação por condição social ou cor; e, sobretudo, por tratamento grosseiro marcado pela impaciência ou indiferença dos profissionais, e por falas de cunho moralista e desrespeitoso. Dentre nossas entrevistadas, a maioria relatou experiências de maus-tratos pessoais ou de outras mulheres em maternidades públicas, demonstrando um consenso em seu meio social de que isso é comum nestes serviços.

"Tinha uma mulher lá do preparo, do pré-parto lá, preparando as mulheres, falou na minha cara: "você não acha que está velha demais não, pra estar parindo?". Falou na minha cara. Falou que eu estava velha pra estar parindo. Eu falei: "não, eu não sou velha. Eu só estou maltratada"; falei pra ela. E ela lá menina, e eu com dor e ela: "se você não calar a boca..." que se eu começasse a gritar que ela ia embora e ia deixar eu lá gritando". (Ester, 32 anos, $2^{\circ}$ filho)

“Eu acho que o maltrato, tratam você como se você... Você já tá ali numa situação constrangedora, né, e assim, a pessoa falar grosso com você, falar grossa, de repente por ela estar com raiva de alguma coisa, ela vim te aplicar uma injeção e te aplicar de qualquer jeito. Eu acho que isso é uma violência, entendeu, dentro da saúde. (Taís)

Desta forma, o mau atendimento, em suas diversas formas, também é reconhecido pelas entrevistadas como uma violência dentro dos serviços de saúde. Como pode ser visto na fala de uma das entrevistadas que, ao invés de cuidada, sentiu-se literalmente 'machucada': 
“E a minha vagina está toda aberta ainda [...] Eu gostaria de mudar, pode ser sincera mesmo? O que eu queria mudar até hoje era a minha vagina. É onde foi costurado, até hoje eu sinto a carne. Não é o ponto, é a carne, doer um pouco. Hoje não está doendo, agora ontem estava doendo muito. Eu fui muito machucada". (Ester)

\section{A "escandalosa": uma questão de gênero}

Observou-se, nos relatos das entrevistadas, um reforço, dentro da instituição, da redução da mulher ao seu papel social de mãe. Ao entrar na maternidade, em muitos casos, a mulher perde sua identidade e se torna apenas "mãe". Várias entrevistadas relataram terem sido chamadas de "mãe" ou "mãezinha" todo o tempo pela equipe médica e, em todos os casos, elas perceberam esta conduta como "normal", "legal", um gesto "carinhoso" por parte da equipe. O apelo ao papel materno geralmente se dá em um contexto em que se busca a conformação da paciente à sua dor, não apenas como algo natural do processo de se tornar mãe como, também, o preço a ser pago pelo exercício de sua sexualidade.

A fala da maioria das entrevistadas demonstra a reprodução ideológica desta naturalização ao confirmarem que faz parte do papel da mulher "boa-mãe" trazer o filho ao mundo e ser forte para aguentar a dor do parto. Esta ideologia é reforçada pelos profissionais que valorizam a paciente que "agüenta calada", que "fica quietinha" e, desta forma, dá menos trabalho.

"Até a enfermeira lá falou assim, a estagiária falou: 'Olha, isso mesmo. Continua assim [quieta] porque geralmente eles judia um pouco quando a mulher dá trabalho'". (Jane)

Essa posição, de sujeito obediente a outro hierarquicamente superior, a que as pacientes são frequentemente chamadas a ocupar, ou seja, da paciente boa como aquela que colabora, é apontada por vários estudos sobre assistência em maternidades, que demonstram a obediência como uma qualidade esperada da paciente (Diniz, Chacham, 2006; McCallum, Reis, 2006; Teixeira, Pereira, 2006; Wagner, 2001).

É nesse contexto que surge, nos relatos das entrevistadas, a figura da paciente "escandalosa": aquela que dá trabalho na hora de parir. O escândalo é definido por elas como: gritar demais e não fazer a força necessária para a expulsão do bebê, berrar, chamar a equipe a todo momento, bater, ficar chamando pelo marido, pela mãe, dizendo que não vai aguentar mais, e ficar mandando tirar o soro. Estas são condutas desvalorizadas pela maioria das entrevistadas e até reprovadas por algumas:

\footnotetext{
“Dependendo da mulher. É bom fazer, né, tem mulher que acha bom ter também o neném, então tem aquelas que gritam, que berram, que quer bater porque não agüentam a dor, e é tanta, né. Então eu acho que tem esse tipo de coisa, mas já acaba se estressando um pouco, aí [acha que deve] deixa[r] ela sofrer um pouquinho de dor. [...] Ó, se a mulher tá lá ela gostou de fazer o neném, por que que ela vai dar murro no médico quando ela vai ter o neném? Eu acho que não tem necessidade disso. Ah, que bom - deixa ela lá sofrer um pouquinho". (Nair)
}

Todas as entrevistadas ressaltaram que, se a mulher fizer escândalo, ela sofrerá maus-tratos dentro das maternidades públicas. Uma informação passada para elas não só por pessoas de seu meio social (mulheres da família, amigas, vizinhas e, até, o marido de uma delas), mas também pelos próprios profissionais de saúde.

“Lá na maternidade tinha uma mulher, já era o quarto filho dela. E a mulher lá, dando as contração, a mulher fazendo um escândalo. E eu lá, era o meu primeiro filho, porque diz que se você não gritar, não fazer escândalo, eles não maltrata. Agora, se você faz escândalo eles maltrata [...] eles deixaram ela de canto lá, reclamando sozinha. Aí elas falava assim: 'Olha o exemplo, hein. A moça aí novinha morrendo de contração e não tá dando um piu e você aí, já no quarto filho e gritando desse jeito? Calma!'. Aí o médico falou assim: 'Só por isso você vai 
ficar aqui agüentando' [...] E eu lá com as contração, eu não dava um piu, eu me mordia, eu puxava minha mão, eu puxava... Dobrava o colchão, ai menina, mas eu não gritava, não fazia nada". (Jane)

Nesse contexto, a estratégia de se calar diante da dor para não sofrer mais é frequentemente utilizada como recurso para escapar da violência institucional: aquela que colabora e não faz escândalo seria mais bem assistida.

A escandalosa, por sua vez, é aquela que não suporta a dor do parto, que é fraca ou descontrolada, mas é aquela que briga pelo que considera ser um direito seu: o de uma assistência que atente para suas necessidades, ainda que elas paguem o preço, algumas vezes, de sofrer sanções. A mulher que grita e faz escândalo pode sofrer repreensões verbais e físicas, como não receber assistência adequada ou ser deixada sozinha, de acordo com nossas entrevistadas, ou mesmo pode ser atendida com maior agilidade.

\footnotetext{
“Ele [o médico] falou assim: 'Ah, mas ela não tá com cara de que tá com dor'. Ah, menina, aí a minha tia falou assim: 'Ah, você quer que ela faça cara que tá com dor? Então eu vou lá fora e falo pra ela fazer um escândalo, então. Porque, se pra você ela tem que fazer escândalo pra mostrar que tá com dor...'. Ele queria que eu fizesse escândalo, entendeu? Que nem aquelas mulher que fica gritando e não sei o que. Aí ele falou assim: 'Não...', aí ele viu que a minha tia era um pouco alterada, né, aí ele falou assim: 'Não, então vamos colocar ela no soro'". (Cléo)
}

No contexto do que é considerado um escândalo, alguns jargões são utilizados na tentativa de conter a paciente: "Está chorando (gritando) por quê? Na hora de fazer não chorou (gritou)". Esse e outros exemplos mostram uma banalização da violência institucional naturalizada em jargões e condutas pautados em estereótipos de classe e gênero, o que favorece a invisibilidade desse tipo de violência que, muitas vezes, é percebida como uma "brincadeira" (Pizzini, 1994) pelos sujeitos envolvidos e até esperada pelas pacientes.

O escândalo também indica uma ruptura do diálogo: a paciente não é ouvida, sua demanda não é acolhida. Ela, por sua vez, também não "ouve" o profissional e não colabora. Não há, portanto, um diálogo que conduza à negociação sobre o compartilhar de responsabilidades e decisões, o que abre espaço para a violência.

Por outro lado, a figura da escandalosa é um bom exemplo das contradições ideológicas que atravessam a relação de poder entre o profissional de saúde e a paciente e, também, um exemplo de resistência das mulheres ao poder médico que subjaz em nossa sociedade.

\section{Relação profissional/paciente: entre o poder e a violência}

O parto hospitalar relatado pelas entrevistadas thes ofereceu pouca ou nenhuma possibilidade de exercício de poder sobre o próprio corpo e suas experiências de parto. Na maioria dos casos, segundo os relatos, as intervenções feitas não foram negociadas, nem explicadas. Boa parte das entrevistadas, por sua vez, também não questionou os profissionais sobre qualquer conduta ou procedimento realizado, e o conhecimento sobre o próprio corpo sequer foi mencionado por elas durante a entrevista. Consideramos que a falta de questionamento das pacientes possa estar amparada no receio delas de que isso fosse recebido pelo profissional como um desrespeito a sua autoridade e ter, como consequência, algum mautrato. A não-valorização do conhecimento sobre o próprio corpo, por sua vez, parece-nos ocorrer em função da expectativa apresentada, pelas entrevistadas, de que o profissional saiba tudo o que deve ser feito e, portanto, a ele caiba a responsabilidade pelas decisões tomadas.

Ainda assim, muitas vezes, a relação com os profissionais, descrita pelas pacientes, não parece estar baseada num vínculo de confiança naquele profissional. Pelo contrário, sobressaem, nos depoimentos, as ameaças, críticas e reprimendas feitas às pacientes como forma de lhes garantir a obediência e deixar clara a hierarquia a que estão submetidas: 
“Ela perguntou assim pra menina se era o primeiro filho, a menina respondeu que era, aí ela falou assim: 'Ah, depois que a gente colocar o soro você vai ver o que é dor. Você nunca teve filho, não?'. Então isso eu não gostei, né. [...] Falou pra menina, mas eu também não gostei, né. Como eu sou mulher, eu também tava grávida, eu também ia passar pela mesma situação que ela". (Ana)

A fala de Ana apresenta uma situação em que paciente e profissional são iguais no gênero, mas desiguais na relação de poder. Na literatura, também encontramos relatos da reprodução de um discurso autoritário e de comportamento hostil com as pacientes por parte de profissionais de saúde mulheres (Teixeira, Pereira, 2006; D’Oliveira, Schraiber, 1999; Jewkes, Abrahams, MVO, 1998). Esta desigualdade se ampara, muitas vezes: em diferenças de classe e etnia; no conhecimento técnico e científico que as profissionais detêm, e numa naturalização ideológica do exercício do poder médico pela posição hierárquica que ocupam. De acordo com D'Oliveira e Schraiber (1999, p.344), "estas profissionais podem ser vistas como um 'duplo', isto é, femininas por situação de gênero e 'masculinas' por condição tecnológica, reproduzindo na enfermagem o poder médico".

O exemplo de Sara ilustra uma violência institucional que deixa clara a falta de ética da profissional. Em uma relação assimétrica de poder, em que Sara se encontra numa posição de maior vulnerabilidade física, emocional e social, sua diferença (ser pobre, nordestina e multípara) é convertida em desigualdade, que a torna inferior, com juízos de valores que subjazem à fala da profissional.

“É, porque acho que tava assim, meio nervosa, né. Ela falou assim: 'Parece que tá no norte. Tá dentro de São Paulo e deixar acontecer isso?'. Mais uma gravidez, né. [...] e ela falou assim: 'Em tempo de morrer e deixar um monte de criança'". (Sara)

Outros relatos, contudo, apontam para uma tentativa de resgate do vínculo de confiança entre a paciente e o profissional, baseado na autoridade técnica e moral deste profissional.

"Aí a médica abriu; apertou aqui; aí viu que não era normal; aí ela: 'mãezinha, calma. Você tem que confiar em mim. Se você não confiar em mim você vai confiar mais em quem?'. Eu falei: 'ó, eu quero que você faça alguma coisa porque esse sangue todo não é normal!'. Já estava vindo aqui em cima de mim ó. Aquele sangue vivinho. Era tanto sangue que se eu não falasse nada eu acho que eu ia morrer lá. Aí como ela viu que não estava normal, me deram lá o remédio, aí parou". (Ester)

Há ainda relatos de um bom manejo de algumas situações por parte dos profissionais de saúde, indicando que há possibilidades mais humanizadas de acolher e lidar com a dor das pacientes. São bons exemplos de profissionais que utilizaram sua autoridade para interromper o ciclo da violência e não o alimentar ainda mais, trazendo dados reais para a paciente, com informações claras sobre o processo de trabalho de parto.

"Aí eu gritava, né, eu gritava, porque vinha tanta dor e eu falava: 'Eu quero cesariana, eu quero cesariana'. 'Eu quero que vocês me corta. Se eu morrer eu vou denunciar vocês.', sabe. Eu lembro como hoje, eu fazia um escândalo e ele falava: 'Calma, mamãe'. Era até um japonês ele, Doutor Emílio. Falou: 'Calma, mãe. Você vai ter bonitinho. Não precisa cesariana. Pra quê eu te cortar se você vai ter ele bonitinho? Você vai ter ele normal, não precisa te cortar'. A única coisa que eles falava era isso". (Olga)

"Fiquei [com vontade de gritar], mas aí depois elas falaram pra mim assim: 'Não, respira fundo, não faz isso, não grita que é pior pra você', aí eu acabei ficando calma. Só gritei na hora que eu vi a cabeça dele, mesmo". (Bel) 
Entretanto, vale ressaltar que apenas fora do ambiente hospitalar, como no momento da entrevista, as pacientes demonstraram sentirem-se seguras para questionarem o atendimento recebido (exames, cuidados com ela e com o bebê, tratamento pessoal e outros procedimentos) sem o risco de qualquer tipo de sanção.

\footnotetext{
"Ai, posso falar que o médico era horrível? [Pode, pode falar. Era horrível, como?] Chato. Sabe quando você chega já deprimida, morrendo de medo, e ele ao invés de animar você, não, ele desanima [...] Duas horas na fila esperando [...] Eu falei pra ele o que tava acontecendo e ele falou então... Aí foram fazer o exame do toque, maldito exame do toque. Porque ele foi com toda vontade. Nossa, acho que doeu mais do que na hora do parto. Por isso que eu não gostei dele". (Dina)
}

Isto evidencia a crise de confiança na relação médico/paciente, à qual se refere Schraiber (2008). O que prevalece são as intervenções e procedimentos técnicos e tecnológicos - o médico faz o seu serviço e vai embora, sem interagir com a paciente enquanto um sujeito. Ela é "objetificada" numa intervenção que, apesar de humana, não é humanizada.

\section{Considerações finais}

No contexto da assistência em maternidades, a paciente é duplamente objetificada: seu corpo é tomado como objeto de controle e domínio da medicina e como meio para se chegar a um fim - o bebê. Essa 'objetificação' traz em si aspectos ligados a uma ideologia de gênero, de dominação do corpo feminino como objeto da medicina enquanto "corpo reprodutor". E se encontra expressa de forma particular na crise de confiança vivida na medicina tecnológica, com a fragilização dos vínculos entre profissionais e pacientes, e uma erosão da qualidade ética de suas interações (Schraiber, 2008). O outro tomado como objeto é, portanto, um 'não-sujeito', na medida em que tem sua subjetividade, sua singularidade, desconsiderada nessa relação.

Outros autores (Martin, 2006; Rego, 2003; Chauí, 1998) também relacionam esse processo de transformação do paciente em mero objeto de intervenção e análise, destituindo-o de sua subjetividade, a uma má ética na prática profissional. Sobre esta questão, Schraiber $(2008,1995)$ escreve que tanto a ética quanto a técnica são dimensões da prática médica, enquanto prática social moral-dependente.

O relato de nossas entrevistadas aponta, também, para uma banalização do sofrimento da parturiente, por exemplo, através da ideologia de naturalização da dor do parto como um preço pelo prazer sexual ou como um destino biológico. A banalização do sofrimento do outro remete à banalização da própria violência institucional, contida em frases que já se transformaram em jargões, adotados sob a aparência de brincadeiras, e na falta de anestesistas de plantão para realização de analgesias durante o trabalho de parto.

Consideramos, apoiados nos estudos de Dejours (2007) e Sá (2005), que esta banalização da violência tanto pode ser o resultado de estratégias de defesa individuais e coletivas, por parte dos profissionais, para lidarem com o sofrimento alheio, quanto reflexo de um fenômeno de banalização da injustiça social que atinge toda a sociedade. Desta maneira, torna-se fundamental o enfrentamento da discriminação e do preconceito de gênero na assistência em maternidades públicas, no sentido do respeito aos Direitos Humanos, e, no âmbito destes, aos Direitos Sexuais e Reprodutivos das pacientes. Para tanto, faz-se importante a desconstrução de uma cultura institucional que banaliza e invisibiliza a violência institucional.

Ressaltamos, ainda, a importância da qualidade ética das interações em uma perspectiva ampla de cuidado, em que tanto as intervenções técnicas como as ações de suporte sejam orientadas para o acolhimento, valorizando a mulher como sujeito na relação profissional/paciente. 


\section{Colaboradores}

As autoras trabalharam juntas em todas as etapas de produção do manuscrito.

\section{Referências}

AGUIAR, J.M. Violência institucional em maternidades públicas: hostilidade ao invés de acolhimento como uma questão de gênero. 2010. Tese (Doutorado) - Faculdade de Medicina, Universidade de São Paulo, São Paulo. 2010.

ARENDT, H. Sobre a violência. Rio de Janeiro: Civilização Brasileira, 2009.

AYRES, J.R.C.M. Cuidado, os modos de ser (do) humano e as práticas de saúde. Saude Soc., v.13, n.3, p.16-29, 2004.

CHAUÍ, M. Ética e violência. Teor. Debate, v.11, n.39, p.32-41, 1998.

Participando do debate sobre mulher e violência. In: CHAUÍ, M.; CARDOSO,

R.; PAOLI, M.C. (Orgs.). Perspectivas antropológicas da mulher. Rio de Janeiro: Zahar, 1985. v.4. p.25-62.

CHIAROTTI, S. et al. Con todo al aire. Reporte de Derechos Humanos sobre Atención en Salud Reproductiva en Hospitales Públicos. Rosario: Instituto de Genero, Derecho y Desarrollo, 2003.

COMITÉ DE AMÉRICA LATINA Y EL CARIBE PARA LA DEFENSA DE LOS DERECHOS DE LA MUJER - CLADEM. CENTRO LEGAL PARA DERECHOS REPRODUCTIVOS Y POLÍTICAS PÚBLICAS - CRLP. Silencio y complicidad: violencia contra las mujeres en los servicios públicos de salud en el Perú. Lima: CLADEM/CRLP, 1998.

D'OLIVEIRA, A.F.P.L.; SCHRAIBER, L.B. Violência de gênero, saúde reprodutiva e serviços. In: GIFFIN, K.M. (Org.). Questões da saúde reprodutiva. Rio de Janeiro: Fiocruz, 1999. p.337-55.

D'OLIVEIRA, A.F.P.L.; DINIZ, C.S.G.; SCHRAIBER, L.B. Violence against women in health-care institutions: an emerging problem. Lancet, v.359, n.11, p.1681-5, 2002.

DEJOURS, C. A banalização da injustiça social. Rio de Janeiro: Ed. FGV, 2007.

DINIZ, C.S.G. Entre a técnica e os direitos humanos: possibilidades e limites da humanização da assistência ao parto. 2001. Tese (Doutorado em Ciências) - Faculdade de Medicina, Universidade de São Paulo, São Paulo. 2001.

DINIZ, C.S.G.; CHACHAM, A.S. O 'corte por cima' e o 'corte por baixo': o abuso de cesáreas e episiotomias em São Paulo. Questões Saúde Reprod., v.1, n.1, p.80-91, 2006.

DOMINGUES, R.M.S.M; SANTOS, E.M.; LEAL, M.C. Aspectos da satisfação das mulheres com a assistência ao parto: contribuição para o debate. Cad. Saude Publica, v.20, supl.1, p.52-62, 2004.

FOUCAULT, M. Microfísica do poder. Rio de Janeiro: Graal, 2007.

O sujeito e o poder. In: RABINOW, P.; DREYFUS, H.L.; FOUCAULT, M. (Orgs.). Uma trajetória filosófica para além do estruturalismo e da hermenêutica. Rio de Janeiro: Forense Universitária, 1995. p.231-49.

GIFFIN, K.M. Corpo e conhecimento na saúde sexual: uma visão sociológica. In: GIFFIN, K.M.; COSTA, S.H. (Orgs.). Questões da saúde reprodutiva. Rio de Janeiro: Fiocruz, 1999. p.79-91.

GOMES, A.M.A.; NATIONS, M.K.; LUZ, M.T. Pisada como pano de chão: experiência de violência hospitalar no nordeste brasileiro. Saude Soc., v.17, n.1, p.61-72, 2008. 
GOULART, L.M.H.F.; SOMARRIBA, M.G.; XAVIER, C.C. A perspectiva das mães sobre o óbito infantil: uma investigação além dos números. Cad. Saude Publica, v.21, n.3, p.715-23, 2005.

HOGA, L.A.K. et al. Relacionamento interpessoal: fator relevante da assistência ao parto na avaliação de puérperas. In: SIMPÓSIO BRASILEIRO DE COMUNICAÇÃO EM ENFERMAGEM, 8., 2002, São Paulo. Anais... São Paulo, 2002. Disponível em: $<$ http://www.proceedings.scielo.br/scielo.php?script=sci_arttext\&pid= MSC0000000052002000100049\&lng=pt\&nrm=iso>. Acesso em: 28 nov. 2009.

HOTIMSKY, S.N. A formação em obstetrícia: competência e cuidado na atenção ao parto. 2007. Tese (Doutorado em Ciências) - Faculdade de Medicina da Universidade de São Paulo, São Paulo. 2007.

HOTIMSKY, S.N. et al. O parto como eu vejo... ou como eu o desejo?: expectativas de gestantes, usuárias do SUS, acerca do parto e da assistência obstétrica. Cad. Saude Publica, v.18, n.5, p.1303-11, 2002.

JEWKES, R.; ABRAHAMS, N.; MVO, Z. Why do nurses abuse patients? Reflections from South African Obstetric Services. Soc. Sci. Med., v.47, n.11, p.1781-95, 1998.

MARTIN, E. A mulher no corpo: uma análise cultural da reprodução. Rio de Janeiro: Garamond, 2006.

MCCALLUM, C.; REIS, A.P. Re-significando a dor e superando a solidão: experiências do parto entre adolescentes de classes populares atendidas em uma maternidade pública de Salvador, Bahia, Brasil. Cad. Saude Publica, v.22, n.7, p.1483-91, 2006.

NOGUEIRA, M.I. Assistência pré-natal: prática de saúde a serviço da vida. São Paulo: Hucitec, 1994.

PIZZINI, F. Communication hierarchies in humour: gender differences in the obstetrical/ gynaecological setting. Disc. Soc., v.2, n.4, p.477-88, 1991.

REGO, S. A formação ética dos médicos: saindo da adolescência com a vida (dos outros) nas mãos. Rio de Janeiro: Fiocruz, 2003.

ROHDEN, F. Uma ciência da diferença: sexo e gênero na medicina da mulher. Rio de Janeiro: Fiocruz, 2001.

SÁ, M.C. Em busca de uma porta de saída: os destinos da solidariedade, da cooperação e do cuidado com a vida na porta de entrada de um hospital de emergência. 2005. Tese (Doutorado em Psicologia) - Faculdade de Psicologia, Universidade de São Paulo, São Paulo. 2005.

SCHRAIBER, L.B. O médico e suas interações: a crise dos vínculos de confiança. São Paulo: Hucitec, 2008.

No encontro da técnica com a ética: o exercício de julgar e decidir no cotidiano

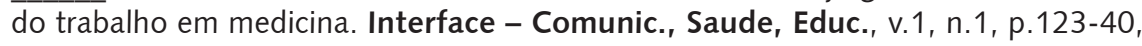
1997.

Pesquisa qualitativa e saúde: reflexões metodológicas do relato oral e produção de narrativas em estudo sobre a profissão médica. Rev. Saude Publica, v.29, n.1, p.63-74, 1995.

SCOTT, J. Gênero: uma categoria útil para análise histórica. Trad. S.O.S. Corpo. Educ. Real., v.16, n.2, p.1-27, 1990.

STARR, P. Orígenes sociales de la soberanía profesional. In: (Org.). La transformación social de la medicina en los Estados Unidos de América. México: Biblioteca de la Salud, Secretaría de Salud, Fondo de Cultura Económica, 1991. 
TEIXEIRA, N.Z.F; PEREIRA, W.R. Parto hospitalar - experiências de mulheres da periferia de Cuiabá-MT. Rev. Bras. Enferm., v.59, n.6, p.740-4, 2006.

TORNQUIST, C.S. Paradoxos da humanização em uma maternidade no Brasil. Cad. Saude Publica, v.19, supl.2, p.419-27, 2003.

VIEIRA, E.M. A medicalização do corpo feminino. Rio de Janeiro: Fiocruz, 2002.

WAGNER, M. Fish can't see water: the need to humanize birth. Int. J. Gynecol. Obstet., v.75, supl.1, p.25-37, 2001.

WORLD MEDICAL ASSOCIATION. Declaration of Helsinki: ethical principles for medical research involving human subjects [on line]. Helsinki, 2000. Disponível em: <http://www.ufrgs.br/bioetica/helsin6.htm>. Acesso em: 15 jan. 2010.

AGUIAR, J. M.; D'OLIVEIRA, A.F.L. Violencia institucional en maternidades públicas bajo el punto de vista en las usuarias. Interface - Comunic., Saude, Educ., v.15, n.36, p.79-91, jan./mar. 2011.

Se presentan y discuten los datos de una investigación sobre violencia institucional en maternidades públicas realizada en el municipio de São Paulo, Brasil. Se entrevistaron 21 puérperas con guión semi-estructurado contando con cuestiones sobre experiencias de parto y asistencia recibida. Según los datos obtenidos, las entrevistadas relatan y reconocen prácticas descriminatorias y tratamiento grosero en el ámbito de la asistencia en maternidades públicas, reaccionando con estrategias de resistencia o de acomodación. Estas experiencias ocurren con tal frecuencia que muchas parturientas ya esperan sufrir algún tipo de maltrato, lo que revela una banalidad de la violencia institucional.

Palabras clave: Violencia institucional. Maternidad. Género.

Recebido em 25/01/10. Aprovado em 12/08/10 